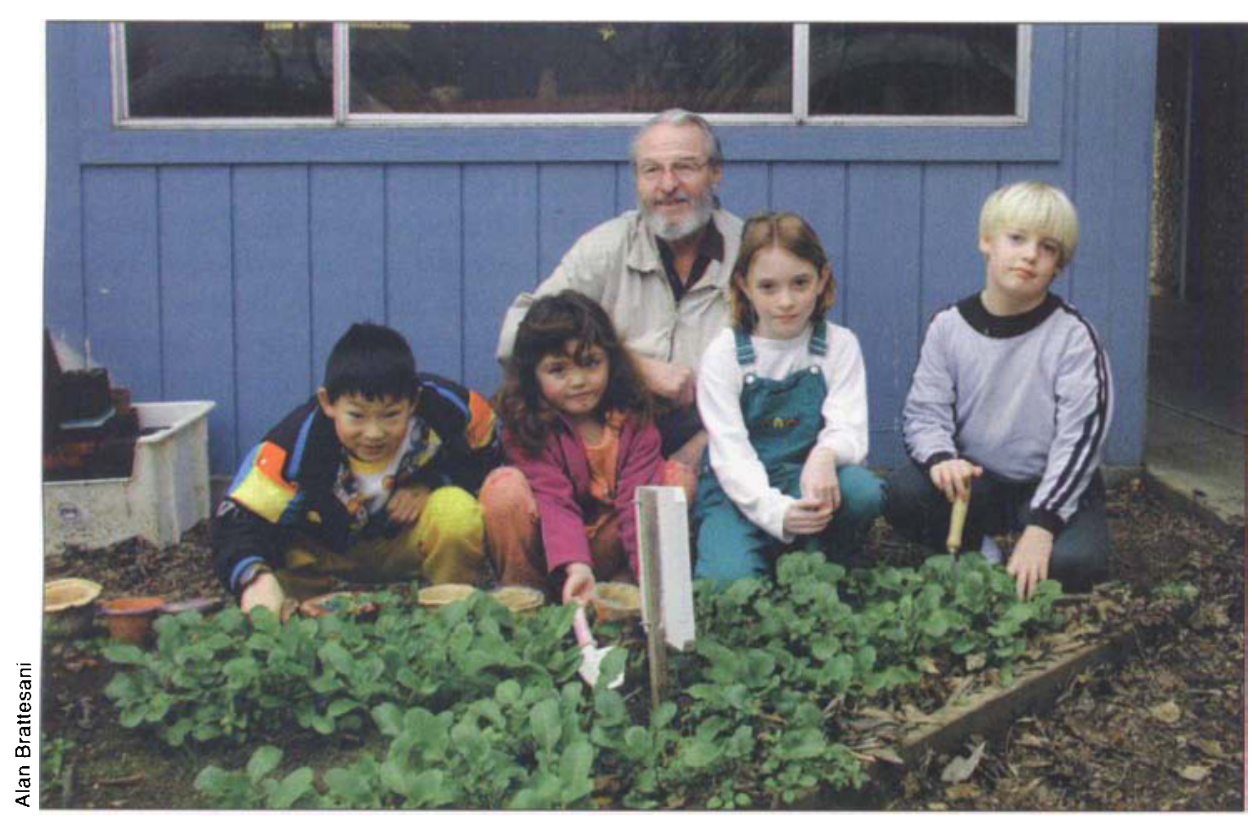

\section{First-grade gardeners more likely to taste vegetables}

\author{
Jennifer L. Morris $\square$ Ann Neustadter $\square \quad$ Sheri Zidenberg-Cherr
}

To encourage first-graders to increase their consumption of fruits and vegetables, a gardenenhanced nutrition education program was developed and taught to them. The study was a pilot to assess the feasibility of garden-based education programs for elementary-school students. The first-grade children learned about nutrition in the classroom while growing vegetables outdoors in their own gardens. This experience resulted in the children's increased willingness to taste those vegetables grown in the gardens. Improving children's desire to taste vegetables is thought to be the first step in developing healthier consumption patterns.

\footnotetext{
Qurrent dietary habits of children are not consistent with national recommendations. For example, recent studies have shown that children consume an average of 3.5 servings of fruits and vegetables each day (KrebsSmith et al. 1996; Muñoz et al. 1997).
}

Birch Lane School students in Davis work out in their geogarden once a week with their garden assistant, Bill Davisson. Study results show that children who work in a garden are more willing to taste vegetables.

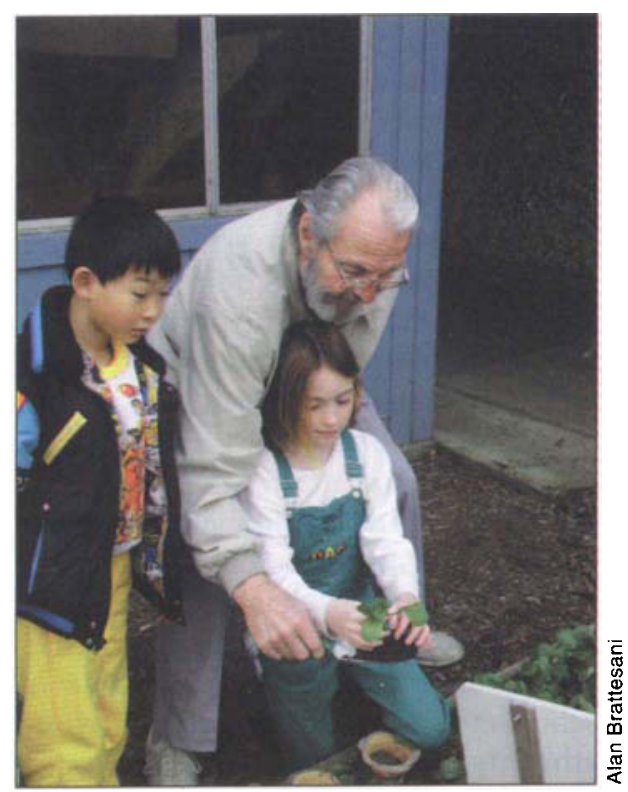

are believed to be influential in behavior change: personal, such as knowledge; behavioral, such as skills; and environmental, such as visual reinforcement (CDC 1996). Programs that are based on this theory must focus on altering all three of these factors to change an individual's behavior. This theory is beneficial when working with young children because they are visual learners and are greatly influenced by their environment.

One way to develop a nutrition education program around the SCT is through the use of a vegetable garden. Gardening provides opportunities to improve students' knowledge and skills related to healthy eating, and it also significantly enhances the environment in which they are learning. Gardening provides the students with hands-on experience through the growing, harvesting and preparation of foods. In addition, gardens provide a wonderful opportunity for foodservice staff, parents and community members to become involved. Garden activities can also teach students about the agricultural value of land in their community. 


\section{Pilot garden study}

The purpose of this pilot study was to assess the initial feasibility of conducting and evaluating a gardenenhanced nutrition education program designed to improve the nutrition knowledge and dietary patterns of first-grade children. The goal was to use these findings to develop and evaluate a comprehensive, gardenenhanced nutrition education program for elementary school-aged children (Morris et al. 2000)

Site selection. Two schools were selected to participate in this study. The California Department of Education (CDE), in collaboration with the U.S. Department of Agriculture, preselected one school to participate in the Team Nutrition Program, and serve as the intervention site. A control school was chosen based on responses to a CDE survey of all California schools, which identified schools with and without gardens. The two schools were matched based on ethnicity of the students and geographic location. Three first-grade classrooms at both sites agreed to participate. Following site selection, the pretest evaluation period began. $\mathrm{Pa}$ rental consent was obtained and all procedures were reviewed and approved by the Committee on the Use of Human Subjects, UC Davis.

Knowledge and preference evaluation. The pretest evaluation consisted of a one-on-one interview with each participating student to assess their knowledge of and attitudes toward food. This procedure was used during the pretest and post-test evaluation periods at the intervention and control sites. Pretests and post-tests were conducted 8 months apart at the intervention site and 6 months apart at the control site. All pretesting took place in the fall and winter, and the post-testing took place in the spring.

The questionnaire consisted of two sections and took 12 to 15 minutes per student to complete. Each student was interviewed individually in his or her language of choice, either English or Spanish. The first part of the tool, the food group identification section, was designed to assess the student's ability to visually identify the food groups. A trained interviewer asked the student to point to pictures of the different food groups as they were mentioned. Students were asked to identify four food groups: fruit, grain, vegetable and dairy. They were also asked to identify the group that you are supposed to eat the most of every day the grain group, according to the U.S. food guide pyramid (USDA 1992). For students who preferred to be interviewed in Spanish, the translations used for fruit, grain, vegetable and dairy were frutas, cereales, verduras and productos de lechería, respectively. Because there are several translations for vegetables and no direct translation for dairy, several texts and native Spanish speakers were consulted.

The second part of the questionnaire, the vegetable tasting section, was designed to assess the student's willingness to taste, preference, and knowledge of a variety of vegetables (Birch 1980). Six vegetables were presented to each student in whole and cut-up form - spinach, carrots, peas, broccoli, zucchini and red bell pepper. All foods were raw and served plain. The student was asked if he or she would like to try any of the vegetables. Students tasted only what they wanted and in their order of choice. Students who tasted a vegetable were asked what they thought of it and to indicate their preference by placing a finger on one of three face pictures ( $(8)$ $=$ did not like it at all; $\Theta=$ it was $\mathrm{OK}$; (:) = really liked it a lot). All three faces were enlarged to fit on one page and were explained to the student prior to tasting. All students were asked if they knew the names of the six vegetables, regardless of whether or not they tasted them. If they did not know the correct name, it was provided to them.

Scoring. Each section of the questionnaire was scored separately. For

\begin{tabular}{|c|c|c|c|}
\hline & $\begin{array}{c}\text { Pretest } \\
\text { Mean } \pm \text { SE }\end{array}$ & $\begin{array}{c}\text { Post-test } \\
\text { Mean } \pm \text { SE }\end{array}$ & $\begin{array}{l}\text { Level of } \\
\text { significance* }\end{array}$ \\
\hline Control & $2.4 \pm 0.2$ & $2.5 \pm 0.2$ & NS \\
\hline Intervention & $1.9 \pm 0.2$ & $2.5 \pm 0.2$ & $P<0.02$ \\
\hline
\end{tabular}

-Between pre- and post-test scores using a 1-tailed paired t-test. the food-group identification section, correct responses received 1 point and incorrect responses received 0 points. A total of 5 points was possible for this section. In the vegetable tasting section, the questions were divided into three groups and totaled separately. The three groups included willingness to taste, preference, and ability to correctly name. For the questions regarding a student's willingness to taste and ability to correctly name, a positive response was given 1 point and a negative response was given 0 points. For the preference question in this section, 2 points were assigned if the student liked a vegetable a lot (-), 1 point if he or she thought it was $\mathrm{OK}(\Theta)$, and 0 points if he or she did not like it (०). These scores were analyzed by the statistical program SPSS (version 10.0.5, SPSS Inc., Chicago IL, 1999). The results were analyzed using the ANCOVA model with the post-test score as the dependent variable, the treatment group as the fixed factor and the pretest score as the covariate. The Bonferroni test was used for followup comparisons of the main effects of the treatment group.

Education intervention. The intervention consisted of education lessons integrated into the existing classroom curriculum. These lessons were taught throughout the entire school year at the intervention site following the pretest data collection period. The lessons were developed by the teachers and were approved by the primary investigators for the study. In general, the teachers were encouraged to teach class material through the use of nutritionrelated examples as well as to spend time on certain nutrition-specific topics, such as the food guide pyramid.

The intervention school also planted, maintained and harvested fall

\begin{tabular}{|c|c|c|}
\hline & $\begin{array}{c}\text { Pretest } \\
\text { Mean } \pm \text { SE (n) }\end{array}$ & $\begin{array}{c}\text { Post-test } \\
\text { Mean } \pm \text { SE (n) }\end{array}$ \\
\hline $\begin{array}{l}\text { Control } \\
\text { Intervention }\end{array}$ & $\begin{array}{l}3.90 \pm 0.30(49) \\
4.07 \pm 0.31(44)\end{array}$ & $\begin{array}{l}3.90 \pm 0.29(49) \\
4.83 \pm 0.23(47) t\end{array}$ \\
\hline Intervention & $4.07 \pm 0.31(44)$ & $4.83 \pm 0.23(47) \dagger$ \\
\hline \multicolumn{3}{|c|}{$\begin{array}{l}\text { "Vegetables included spinach, carrots, peas, broc- } \\
\text { coli, zucchini and red bell pepper. } \\
\text { †Significantly different from pretest, } P<0.005 \text {, fol- } \\
\text { lowing ANCOVA and follow-up linear regression. }\end{array}$} \\
\hline
\end{tabular}


and spring gardens. Various vegetables were grown, including spinach, carrots, peas and broccoli. The students were directly involved with all work done in the gardens. Parents and community members were encouraged to get involved. Once the vegetables were harvested, the students worked with their teachers and the school food-service staff to prepare dishes. The investigators provided no formal nutrition or gardening education to the students at the control site.

\section{Program effectiveness}

A total of 97 first-grade students participated in the study (48 intervention, 49 control). The sections of the questionnaire, food group identification and vegetable tasting, were analyzed separately. When analyzed by site, students at the intervention site showed a significant improvement in their ability to visually identify the food groups. No significant change was seen at the control site (table 1). When we took the pretest scores into account, education did not significantly affect their ability to visually identify the food groups.

The results for the vegetable tasting section were more encouraging. Spinach, carrots, peas and broccoli were grown in the gardens at the intervention site, and none at the control site. At the time of the post-test, the students in the intervention group were more willing to taste these vegetables than students in the control group ( $\mathrm{F}=$ $11.012, p<0.005$ ) (table 2). The preference data showed that on average, the students gave all of the vegetables a score of 1.25 (score range was 0 to 2 ) or greater (data not shown). Preferences for the vegetables were not significantly affected in either group. No significant improvements were seen in the students' ability to correctly name the vegetables in either group.

\section{Nutrition education studies}

Policy-makers and nutrition experts are increasingly aware that nutrition education in the school setting is necessary to improve the eating habits of young children. To date, reviews of the literature have shown that education programs based on theoretical frameworks appear to be most effec-

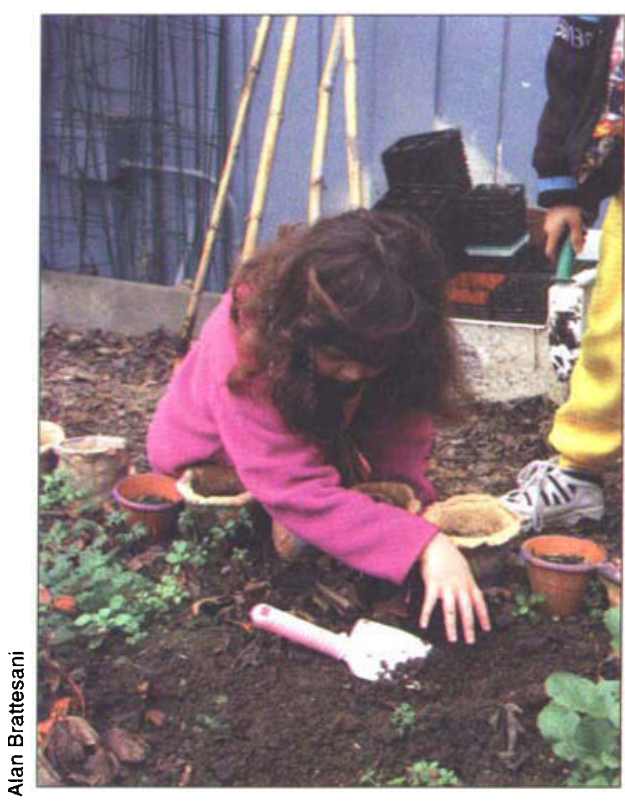

A willingness to taste vegetables is an essential step in improving a child's food preferences.

tive. Vegetable gardens are an excellent means of fitting a nutrition education program into a theoretical framework.

The objective of this pilot study was to assess the feasibility of completing a garden-enhanced nutrition education program within the constraints of a traditional school year, while incorporating it into a workable study design. We found that vegetable gardens could be planted, grown and harvested during the school year, with time for investigators to collect posttest data before the students left for summer break. This study lends support to the inclusion of garden-based education in the school setting.

Age sensitivity. The evaluation was focused on first-grade students, based on the current knowledge that the earlier a child is introduced to healthy eating habits, the more likely he or she is to continue them throughout life (Kelder et al. 1994; KrebsSmith et al. 1995). However, young students can only complete limited forms of assessment. As a result, this pilot study demonstrated that subsequent studies should focus on a slightly older group of students to allow for more detailed evaluation.

Students in the intervention group showed a significant improvement in their ability to visually identify specific food groups. However, since the pretest scores were higher in the control group, the significance of the knowledge improvement disappeared when the data were analyzed using analysis of covariance. This lack of significant knowledge improvement was probably due to the limited number of knowledge-related questions asked. The visual methodology used in this study was selected because first-graders are generally better at visual than verbal identification. In addition, young children can be hesitant about talking with strangers.

Methodology. Other investigators have validated the methodology used for the vegetable tasting section (Birch 1979). Allowing children to actually taste foods during the interview provides a more accurate account of their true preferences (Birch 1979). On average, over $50 \%$ of the students were willing to taste the raw vegetables presented to them. Results showed that all students were equally willing or unwilling to taste the vegetables regardless of ethnicity (data not presented). Raw vegetables were used for the study due to a lack of cooking facilities. The carrots were included solely as a way to encourage the children to taste vegetables and feel more comfortable with the process since the children were already familiar with carrots. Because all pretesting was done in the winter and fall, and posttesting in the spring, attempts were made to control for variations in vegetable quality. All vegetables were purchased at the same store and prepared in the same manner for all evaluation periods.

The students in the intervention group were more willing to taste the vegetables presented to them than the control students. It is exciting to note that only some of the vegetables were grown in the gardens at the intervention school and incorporated into the in-class education lessons, yet the gardening increased the children's awareness of and willingness to taste several vegetables. Future garden projects should aim to increase the variety of foods grown.

Exposure to vegetables. Vegetable preferences were measured because there is evidence that they predict dietary behavior (Harvey-Berino 


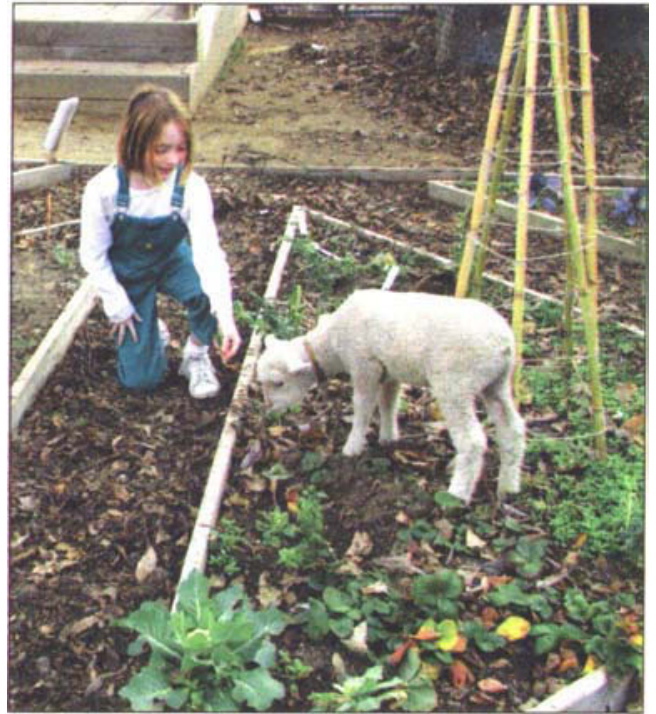

To improve children's awareness of and willingness to taste different vegetables, future garden projects should aim to increase the variety of foods grown.

et al. 1997). Preference correlates with exposure; however, this is significant only when the exposure includes tasting the food item (Birch and Marlin 1982). The first step toward improving a child's food preferences is to increase his or her exposure to a variety of foods. The gardening experience obviously increased the children's exposure to the vegetables. The second, and more crucial, step is to increase the children's willingness to taste these vegetables. The results show that vegetable gardening was an effective means of increasing the children's willingness to taste. However, there is also evidence suggesting that 10 to 15 tasting opportunities are necessary before a child's preference improves (Birch et al. 1987). The preference results are probably a reflection of an inadequate number of taste-testing opportunities during the education program.

Food identification. The final portion of the questionnaire asked the children to name the vegetables presented to them. After providing an answer, the student was told the correct name of the vegetable. No significant differences were seen in the students' ability to correctly name the vegetables in either group. This could be because this was the only question during the entire interview that required students to speak to the interviewer. Many of the young students interviewed were quite shy and may not have felt comfortable talking to someone they didn't know. Translations seemed to pose some complications. Several translations for each word were accepted as correct. Spanish translations were also accepted from the students who were interviewed in English if the child was known to be bilingual.

In conclusion, it is feasible to conduct a garden-enhanced nutrition education program within the constraints of a school year and a study design. Although the education did not improve the children's ability to visually identify the food groups, the students who grew the vegetables in their gardens were more willing to taste certain vegetables. Again, this is an essential step in improving a child's food preferences. Food preferences did not change, but that may simply indicate that more tasting opportunities should be offered during the course of the lessons. The school lunch program provides an ideal avenue to increase children's exposure to and tasting of new fruits and vegetables. This may aid in improving their preferences for a variety of foods. The more vegetables they prefer, the more they are likely to eat.

School gardens are an exciting new area with great potential for behavior change; however, there are several issues that must be considered in subsequent studies. First, the effectiveness of the program lies partly in the validity of the assessment tools used. Simply watching the students indicated that the garden-enhanced nutrition education lessons were very effective. However, it is essential that future studies use tested assessment tools that are better able to detect smaller changes and other psychosocial factors. Second, a more comprehensive curriculum needs to be developed that adequately synthesizes several important aspects of nutrition and health. Ultimately, it will be beneficial to develop a garden-enhanced nutrition education curriculum for use by all grades at the elementaryschool level.

J.L. Morris is Ph.D. Candidate, A. Neustadter is Research Assistant and S. Zidenberg-Cherr is Nutrition Science
Specialist, Department of Nutrition, UC Davis.

The authors acknowledge the cooperation of the teachers and staff at the two schools involved, St. Helena Elementary School and McPherson Elementary School, which is in Napa, as well as all of the undergraduate students who provided technical assistance. Thanks also to Jan Peerson for statistical advice. This study was funded in part by the Nutrition Education and Training Program, California Department of Education, Sacramento.

\section{References}

Birch LL. 1979. Preschool children's food preferences and consumption patterns. J Nutr Educ 11(4):189-92.

Birch LL. 1980. Effects of peer models' food choices and eating behaviors on preschoolers' food preferences. Child Dev 51:489-96.

Birch LL, Marlin DW. 1982. I don't like it; I never tried it: Effects of exposure on 2-yearold children's food preferences. Appetite 3:353-60.

Birch LL, McPhee L, Shoba BC, et al. 1987. What kind of exposure reduces children's food neophobia? Looking vs. tasting. Appetite 9:171-8.

[CDC] Centers for Disease Control and Prevention. 1996. Guidelines for school health programs to promote lifelong healthy eating. MMRW 45(RR-9):1-41.

Contento I, Balch Gl, Bronner YL, et al. 1995. Theoretical frameworks or models for nutrition education. J Nutr Educ 27(6):287-90.

Harvey-Berino J, Hood V, Rourke J, et al. 1997. Food preferences predict eating behavior of very young Mohawk children. J Am Diet Assoc 97(7):750-3.

Kelder SH, Perry CL, Klepp K, Lytle LL. 1994. Longitudinal tracking of adolescent smoking, physical activity and food choice behaviors. Am J Public Health 84(7):1121-6.

Krebs-Smith SM, Cook A, Subar AF, et al. 1996. Fruit and vegetable intakes of children and adolescents in the United States. Arch Pediatr Adolesc Med 150(1):81-6.

Krebs-Smith SM, Heimendinger $\mathrm{J}$, Patterson BH, et al. 1995. Psychosocial factors associated with fruit and vegetable consumption. Am J Health Promotion 10(2):98-104

Lytle L, Achterberg C. 1995. Changing the diet of America's children: What works and why? J Nutr Educ 27(5):250-60.

Morris J, Briggs M, Zidenberg-Cherr S. 2000 . School-based gardens can teach kids healthier eating habits. Cal Ag 54(5):40-6.

Muñoz KA, Krebs-Smith SM, BallardBarbash R, Cleveland LE. 1997. Food intakes of US children and adolescents compared with recommendations. Pediatrics 100(3):323-9.

[NRC] National Research Council. 1989. Diet and health: Implications for reducing chronic disease risk. Washington, DC: National Academy Press. $386 \mathrm{p}$.

[USDA] US Department of Agriculture. 1992. The food guide pyramid. Home \& Garden Bul No 252. 